\title{
Narrativa, memória e saberes: entrevista com o professor Reiner Hildebrandt-Stramann
}

\author{
Narrative, memory and knowledge: interview with the teacher Reiner Hildebrandt-Stramann \\ Narrativa, memoria y conocimiento: entrevista con el profesor Reiner Hildebrandt- \\ Stramann
}

Janice Zarpellon Mazo, Tuany Defaveri Begossi ${ }^{\mathrm{II}}$

\begin{abstract}
Resumo
A presente entrevista busca registrar no contexto da Universidade Federal de Santa Maria (UFSM), especialmente em virtude das comemorações dos 50 anos do Centro de Educação Física e Desportos (CEFD), o testemunho de Reiner Hildebrandt-Stramann, um dos professores que subscreveu sua influência na referida instituição e no campo da Educação Física brasileira. A narrativa propõe rememorar, de modo particular, o período em que o professor dividiu suas ideias, compreensões e pensamentos sobre a Educação Física, no CEFD/UFSM. O testemunho sinaliza, especialmente, os sentidos e significados percebidos pelo docente sobre a recepção de sua proposta de intervenção relacionada às aulas abertas à experiência, na referida instituição. Sublinha-se que esta concepção de ensino contribuiu para a mudança de paradigma em relação ao movimento humano no contexto escolar brasileiro e colaborou para a legitimação da Educação Física neste âmbito.
\end{abstract}

Palavras-chave: História da Educação Física; Concepções pedagógicas; Formação de professores

\begin{abstract}
This interview aims to record in the context of the Federal University of Santa Maria (UFSM), especially in view of the celebrations of the 50th anniversary of the Center for Physical Education and Sports (CEFD), the narrative of Reiner Hildebrandt-Stramann, one of the teachers who subscribed its influence in that institution and in the field of brazilian Physical Education. The narrative proposes to recall, in a particular way, the period in which the teacher shared his ideas, understandings and thoughts about Physical Education at CEFD/UFSM. The testimony signals, especially, the senses and meanings perceived by the teacher about the reception of his intervention proposal related to classes open to the experience, in that institution. It is emphasized that this conception of teaching contributed to the paradigm shift in relation to the human movement in the Brazilian school context and contributed to the legitimation of Physical Education in this environment.
\end{abstract}

Keywords: History of Physical Education; Pedagogical conceptions; Teacher qualification

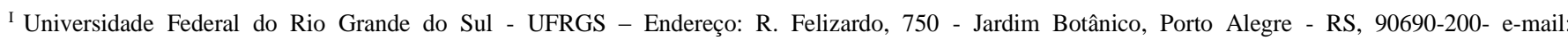
janice.mazo@ufrgs.br

${ }^{\text {II }}$ Universidade Federal do Rio Grande do Sul - (UFRGS - e-mail: tuany begossi@hotmail.com
} 


\section{Resumen}

La presente entrevista busca registrar en el contexto de la Universidad Federal de Santa María (UFSM), especialmente debido a las celebraciones del 50 años del Centro de Educación Física y Deportes (CEFD), el testimonio de Reiner Hildebrandt-Stramann, uno de los maestros que suscribió a su influencia en esa institución y en el campo de la Educación Física brasileña. La narrativa propone recordar, de una manera particular, el período que el maestro compartió sus ideas, entendimientos y pensamientos sobre Educación Física, en CEFD/UFSM. El testimonio señala, especialmente, los sentidos y significados percibidos por el maestro sobre la receptividad de su propuesta de intervención relacionada con las clases abiertas a la experiencia, en la institución referida. Se enfatiza que esta concepción de la enseñanza contribuyó al cambio de paradigma en relación con el movimiento humano en el contexto escolar brasileño y ayudó a legitimar la educación física en ese entorno.

Palabras clave: Historia de la educación física; Conceptos pedagógicos; Formación de professores

"Pensar em memória e em história induz a referir-se ao sujeito que evoca e ao sujeito que escreve, este agente do ato de presentificar uma ausência" (PESAVENTO, 2008, p. 189).

Para Sandra Pesavento (2008, p. 189), o ato de presentificar uma ausência liga-se a construção e ao registro de uma leitura sobre o passado. O depoimento, neste particular, convoca essa temporalidade escoada através do que foi retido pela memória, tornando-se inteligível através da narrativa. As habilidades da retórica, por sua vez, possibilitam o acesso a subjetividades, trajetórias pessoais e histórias de vida, as quais, conformam-se enquanto releituras, reinterpretações e reformulações do passado vivido e não como uma reprodução do real.

Acerca desta dimensão, Gaddis (2003, p. 157-158) nos diz que a "realidade não é apenas a experiência, é a experiência imediata", ou seja, à medida com que pensamos sobre a realidade, "nós a deformamos ao destruir seu aspecto imediato, e assim o pensamento nunca alcança a realidade". Deste modo, apoiando-nos em tais reflexões, compreendemos o passado narrado enquanto uma representação que, mesmo destituída de seu imediatismo, é portadora de uma leitura e visão de mundo particulares. Tais pressupostos, sustentam o presente texto, o qual vislumbra inscrever na tessitura do tempo da Universidade Federal de Santa Maria (UFSM), especialmente em virtude das comemorações dos 50 anos do Centro de Educação Física e Desportos (CEFD), o testemunho de um dos professores que subscreveu sua influência não apenas na referida instituição, mas, no próprio campo da Educação Física brasileira.

Os anos de 1980 demarcaram um período em que a Educação Física em cenário nacional, começou a problematizar e a questionar algumas das concepções em vigência, especialmente aquelas de ordem pedagógica. Na baliza de tais discussões, figuravam críticas a visões de ensino tradicionais, as quais 
conduziam, também, o processo de formação profissional da área, no referido período. Este contexto também coincide com a criação do curso de Mestrado em Ciência do Movimento Humano, do CEFD/UFSM, o qual se constituiu, no ano de 1979, como o segundo programa de pós-graduação stricto sensu na área da Educação Física, implementado no país.

Os novos paradigmas pedagógicos da Educação Física brasileira, também conhecidos no tempo presente como "Movimentos Renovadores", juntamente com o impacto da implementação do curso de Mestrado em Ciência do Movimento Humano, contribuíram para que ocorressem uma série de ações no CEFD, na tentativa de reordenar a constituição da área, buscando ampliar suas compreensões. De modo específico, sublinhamos que havia uma preocupação centrada no ensino da Educação Física em nível escolar e, conforme mencionado, na própria formação de professores(as). Assim, dentre ações levadas a feito na época, destacamos o convênio que possibilitou a vinda de professores alemães para atuar junto ao CEFD/UFSM e a influência de suas produções para os novos contornos que estavam se configurando na Educação Física brasileira.

A vinda do Prof. Dr. Reiner Hildebrandt-Stramann ${ }^{1}$ para o Brasil resultou do convênio entre o Serviço Alemão de Intercâmbio Acadêmico (DAAD), a Coordenação de Aperfeiçoamento de Pessoal de Nível Superior (CAPES) e o Conselho Nacional de Desenvolvimento Científico e Tecnológico (CNPq), com a finalidade de atuar junto ao curso de mestrado em Ciência do Movimento Humano do CEFD/UFSM (MAZO, 1997). Contudo, para além de atuar como professor visitante no período de 1984 a 1986 na UFSM, anos depois, em 1989, também atuou na Universidade Federal de Pernambuco (UFP), além de outras instituições de ensino federais e estaduais do país localizadas nas cidades de Maringá/PR, Maceió/AL, Campinas/SP, Florianópolis/SC e Vitória/ES. Em decorrência da significativa atuação de HildebrandtStramann no Brasil e, de modo específico no CEFD/UFSM, trazemos no presente texto, o registro de sua narrativa.

A entrevista com o Prof. Reiner - eu assim o chamava pela facilidade de pronúncia do primeiro nome em relação ao sobrenome - foi viabilizada pelo professor Eleonor Kunz. Em conversa com o professor Kunz, mencionei que tinha interesse em entrevistar o Prof. Reiner para uma pesquisa que estava desenvolvendo sobre história do CEFD da UFSM, a qual foi publicada em formato de livro comemorativo dos 25 anos do CEFD (1970-1995) (MAZO, 1997). Então, o professor Kunz disse que tentaria uma forma de realizar a entrevista já que encontraria o Prof. Reiner quando fosse para a Alemanha.

Eu nunca falei com o Prof. Reiner, afinal, eu era apenas uma aluna caloura, que recém havia ingressado, no ano de 1984, no curso de Licenciatura em Educação Física do CEFD/UFSM e, ainda, por

${ }^{1}$ A partir do ano de 1990, Reiner Hildebrandt passou a assinar Reiner Hildebrandt-Stramann. 
ser tímida, raramente me dirigia a um professor(a). No entanto, tive a oportunidade de ouvir o Prof. Reiner em alguns eventos e ocasiões. Além disso, desenvolvi na disciplina de estágio, aulas em uma escola pública de Santa Maria, tendo como referencial “as concepções abertas de ensino”, proposta difundida pelo Prof. Reiner juntamente a um grupo professores que cursava mestrado no CEFD/UFSM. Um deles foi meu supervisor do estágio na escola - o professor Luis Fernando Cardoso - que encorajou um pequeno grupo de alunos(as) a romper com o chamado "modelo tradicional" de ministrar aulas de Educação Física na escola. Foi um período que fez diferença na minha formação acadêmica e profissional, acrescentando conhecimentos e experiências que, até então, não tinha vivenciado: reuniões de estudo, leituras de textos, escrita e apresentação de trabalhos em eventos, análise de filmagem de aulas de Educação Física na escola, dentre outras.

Algum tempo depois, o professor Kunz fez contato comigo dizendo que estava com viagem marcada para a Alemanha e que, então, realizaria a entrevista com o Prof. Reiner. Não lembro exatamente do mês, mas, a entrevista ocorreu no ano de 1995. Elaborei uma pequena carta que continha explicações sobre minha pesquisa e perguntas sobre o tempo que o Prof. Reiner esteve no CEFD/UFSM.

Professor Reiner Hildebrandt-Stramann: Eu recebi a sua carta e queria respondêla através da entrevista com seu colega Elenor Kunz. Nós estamos agora, aqui em Hannover, e tentamos responder suas perguntas na carta. Espero que as respostas sanem suas perguntas e quando você tiver mais questões, você pode entrar em contato comigo, através de mais cartas.

A entrevista com o Prof. Dr. Reiner Hildebrandt-Stramann nos propõe uma viagem de volta aos anos em que dividiu com alunos(as) e professores(as) da UFSM suas ideias, compreensões e pensamentos sobre a Educação Física. A narrativa inicia com a rememoração do tempo em que esteve na cidade de Santa Maria/RS, atuando no CEFD/UFSM.

Professor Reiner Hildebrandt-Stramann: Bem, eu estive em Santa Maria entre 1984 e 1986. Cheguei em agosto de 1984 e fiquei dois anos em Santa Maria e no Recife. Minha tarefa foi trabalhar, quase que exclusivamente, com o mestrado, mas, também, fiz alguns cursos na especialização e alguns cursos com graduação.

O Prof. Reiner atuou de modo particular na área pedagógica, voltada ao ensino da Educação Física na escola. Conforme mencionado em sua narrativa, além de ministrar aulas no curso de mestrado, também ofereceu cursos para alunos(as) da graduação, atuando junto à disciplina de Ginástica ministrada, no período, pela professora Ingrid Mariane Becker, bem como proferiu aulas no curso de especialização. Acerca deste ponto o Prof. menciona que "o contato com a graduação foi realizado junto a alguns colegas, 
como a professora Ingrid. Eu fiz cursos, mais voltados à prática da formação dos estudantes da graduação. Eu fiz um curso de ginástica na graduação e um curso de capoeira”.

Reiner sucedeu outros professores alemães que também permaneceram por um período no CEFD, atuando no curso de mestrado. Em sua narrativa Hildebrandt-Stramann rememora que foi "quase um seguidor do Dieckert”. O professor Jürgen Alfred Friz Dieckert, da Escola Superior de Esporte da República Federal da Alemanha, também atuou na condição de professor visitante no mestrado do CEFD e, do mesmo modo que o professor Hildebrandt-Stramann, veio ao Brasil com o apoio do convênio DAAD/CAPES/CNPq, no ano de 1980 (MAZO, 1992). Dieckert ${ }^{2}$ foi o primeiro a trabalhar na UFSM por intermédio do referido convênio e sua estadia na instituição teve por finalidade o próprio estabelecimento do curso de mestrado no CEFD, além do intuito de conformar a criação de um núcleo pedagógico na área da Educação Física. Tal contexto foi rememorado pelo Prof. Reiner em sua narrativa, mencionando que " $a$ intenção foi de implantar um curso de mestrado, com professores alemães, com o intuito de formar um núcleo pedagógico. O Dieckert iniciou o projeto [...] e eu fui na consequência”. Vale anotar, que tive a oportunidade de experenciar, como aluna do curso de graduação, um dos projetos implantados pelo professor Dieckert: o "Esporte para Todos" (EPT). Durante os anos que cursei a graduação fui bolsista voluntária do projeto e nos finais de semana e feriados, a "Equipe do EPT" promovia atividades como jogos e brincadeiras em localidades da região e nas Ruas de Lazer, as quais eram abertas à comunidade.

É válido registrarmos que, antes de Hildebrandt-Stramann chegar à UFSM, Dietmar Kleine, também professor alemão, esteve no CEFD. Dietmar, contudo, tinha seus estudos voltados à área da Psicologia do Esporte e da Aprendizagem Motora ${ }^{3}$ e, do mesmo modo, veio para o Brasil através do convênio do DAAD/CAPES/CNPq. Em seu relato, o professor Reiner menciona:

Professor Reiner Hildebrandt-Stramann: Depois do Dieckert, esteve Dietmar Kleine [...], mas, o Dietmar Kleine foi com uma outra intenção. A intenção de Dietmar foi na área mais da psicologia do esporte e da aprendizagem motora, $e$ não da pedagogia. Minha tarefa foi continuar o trabalho que o Dieckert iniciou na área pedagógica.

\footnotetext{
${ }^{2}$ Em seu primeiro ano no CEFD, implantou a proposta chamada "Esporte para Todos", argumentando que a Educação Física escolar brasileira deveria ter o esporte de alto nível como base da formação. No ano seguinte, Jürgen Dieckert foi coordenador do programa "MEXA-SE" dentro da campanha do "Esporte para Todos", destinado aos professores e funcionários da universidade. O trabalho do professor Jürgen Dieckert não se restringiu a Santa Maria, realizando cursos em outras cidades brasileiras, principalmente, sobre o tema criatividade na Educação Física. Permaneceu no país até o ano de 1983 (MAZO, 1992). ${ }^{3} \mathrm{Na}$ edição do curso de Especialização em Técnica Desportiva do CEFD do ano de 1983, o professor Dietmar Kleine foi convidado a atuar, em caráter eventual, nas áreas de Psicologia do Esporte e Aprendizagem Motora (MAZO, 1993).
} 
Neste caminho, solicitou-se ao Prof. Hildebrandt-Stramann que rememorasse o processo que convergiu para que ele e outros professores alemães viajassem ao Brasil, com o intuito de contribuírem para o desenvolvimento do campo da Educação Física e, especificamente, para atuarem em prol do estabelecimento de alguns contornos pedagógicos à área. Acerca deste aspecto, na entrevista realizada destacou-se que é notória a influência que ele e seus colegas alemães tiveram no delineamento da própria "ciência" da Educação Física e do Esporte em nosso país, sobretudo, através dos recursos humanos formados também por eles, nos cursos de mestrado em que atuaram. Por outro lado, o que ainda não estava manifesto eram os inconvenientes que surgiram neste caminho e que precisaram ser enfrentados, principalmente, pelos professores alemães que demostraram ter uma ideia um pouco diferente daquela que era dominante na Educação Física brasileira daquele período e que, por sua vez, era defendida por colegas professores(as) da instituição. Acerca deste aspecto o Prof. Reiner menciona:

Professor Reiner Hildebrandt-Stramann: Bem, a questão da importância para o mensageiro realmente é muito dificil recordar quando a gente recebe, aqui na Alemanha, informação que a gente pode trabalhar num outro pais, numa outra cultura e decidir o grau de importância, porque, primeiramente, é uma decisão quase que subjetiva, porque é importante, em primeiro lugar, para mim mesmo. Foi ansioso, curioso conhecer uma outra cultura, conhecer outras pessoas e conhecer como a questão de movimentar-se numa outra cultura está configurada, como está resolvida. Isto está em primeiro.

Na sequência, ele prossegue:

Professor Reiner Hildebrandt-Stramann: Eu queria conhecer, mas, se tinha, também, a intenção de querer ampliar essa compreensão. Na minha opinião, as culturas de movimentar-se se diferem, porque, por exemplo, na Alemanha, isso foi meu ponto de saída. Na Alemanha nós tivemos, também nessa época, uma discussão forte sobre uma ampliação do conceito esportivo. Junto com essa discussão aconteceu outra sobre a modificação da Educação Física escolar. Por isso, meu conhecimento foi muito ingênuo de que uma cultura na América do Sul deveria ter uma compreensão muito ampla da questão de movimentar-se, porque, quando vivem num pais, também vivem muitas culturas diferentes. Essas culturas diferentes devem ter diferentes visões de movimentar-se. Então, para mim primeiramente, era importante conhecer essas culturas e, segundo, então, ampliar e, também, ver como funciona. Então, agora, deve-se pensar a transmissão desta questão para as crianças nas escolas. Como a gente pode configurar essa didática de ensino? Isso foi minha "profissão", ver como é interessante o funcionamento dessa configuração didática de movimento. Então, isso, foi o primeiro.

A narrativa do Prof. Hildebrandt-Stramann foi conduzida no sentido de evidenciar, inicialmente, quais foram os princípios que conduziram o seu trabalho na UFSM. Deste modo, fez questão de destacar 
em sua narrativa que seu anseio não foi o de aplicar um modelo fechado, trazido da Alemanha. Ao contrário disso, sua prática foi permeada pelo desejo de primeiro, conhecer como se relacionava a questão do "movimentar-se" com o contexto de vida dos escolares, na realidade específica na qual estava se inserindo e, além disso, relacionar tais aspectos com o próprio ensino sucedido na universidade. Tais premissas demonstram, de certa forma, uma sensibilidade do professor Reiner, especialmente em razão de sua preocupação em buscar compreender a realidade na qual se encontrava para, então, efetivar sua intervenção.

Professor Reiner Hildebrandt-Stramann: Antes de responder a essa pergunta, eu quero explicar como eu tentei realizar minhas disciplinas no curso [...]. Pensei o seguinte exemplo: como tu te sentirias quando no teu colégio ou no teu departamento chegasse um dia um japonês e quisesse explicar como funciona a Educação Física? Então, essa foi minha primeira imagem. Eu pensei: se um japonês chegasse aqui e quisesse explicar para mim como eu devo fazer aulas de Educação Física, eu responderia: senhor, eu acho que você tem muito conhecimento e tem uma grande experiência, mas, por favor, fica um pouco mais distante. Realmente, foi com esse pensamento que cheguei no Brasil e tentei, primeiramente, dar distância e observar. Esse foi meu primeiro procedimento científico. Tentei observar o que acontecia no mundo vivido e nas escolas. Tentei me dirigir aos alunos através desse método de observação. Tentei introduzir meus alunos de mestrado através desse método, em algumas questões científicas da investigação.

Após ter demarcado seu ponto de partida, o Prof. Reiner menciona como ocorreu a recepção desta proposta, por parte da comunidade acadêmica, apresentando uma situação a fim de exemplificar:

Professor Reiner Hildebrandt-Stramann: Por exemplo: investigação sobre o ensino. O que eu fiz: fui com uma câmera de vídeo para uma escola e filmei. Gravei aulas de Educação Física. Com estas aulas eu voltei para a universidade e apresentei essas aulas de Educação Física para os colegas do mestrado. O nome do curso foi "Análise e Planejamento das aulas de Educação Física: uma reflexão crítica”. Então, não falei nada sobre ensino aberto, nada. Apresentei as aulas filmadas, mas, levei também aulas da Alemanha. Aulas filmadas da Alemanha para o Brasil. Apresentei o vídeo e, também, outros exemplos das aulas de Educação Física. Nós analisamos esses exemplos do Brasil e esses exemplos da Alemanha. Analisamos: "o que significa aqui?". Bem, eu apresentei algumas teorias de análise, algumas teorias de reflexão. Isso foi necessário, mas, usei também na apresentação dessas teorias, algumas teorias brasileiras que eu conheci. Uma teoria da educação do Paulo Freire. A gente poderia usar algumas concepções dele numa análise aprofundada das aulas de Educação Física. Então, aqui, usei métodos etnológicos, métodos da etnologia, etc, etc. [...]. Essa foi minha tentativa. Dei o primeiro passo para a fase de distanciar os alunos da própria realidade, mas, havia um vínculo quase que ingênuo da realidade. Então, achei que através dessas apresentações diferentes, que através disso, eu abriria para os colegas do mestrado 
alguns olhos. Tentei, eu acho que consegui que eles começassem a refletir sobre o próprio ensino, não só na escola. Eu perguntei: como funciona a transmissão dos conteúdos também na formação? Esse foi o segundo ponto e, o terceiro, foi: como funciona essa transmissão no mundo vivido? Esses eram meus três pontos principais, na formação pedagógica dos meus mestrandos.

Os estudos do Prof. Hildebrandt-Stramann centravam-se na realização de pesquisas didáticas relacionadas, especialmente, a compreensão de aulas abertas à experiência, problematizando teorias pedagógicas ligadas ao "movimentar-se" e ao desenvolvimento pedagógico na escola (OLIVEIRA, 2005). A entrada de tais concepções em cenário nacional, podem ter atuado como catalizadoras de um movimento mais amplo, que passou a questionar o modo como a Educação Física, o movimento e o próprio esporte eram tratados na escola e, consequentemente, na formação de professores(as) da área. Ao dedicar-se a discutir a Educação Física, tendo por guisa a compreensão fenomenológica, Hildebrandt-Stramann direcionou o olhar à experiência como ponto crucial a ser levado em consideração no desenvolvimento das ações da área, no âmbito escolar.

Deste modo, Hildebrandt-Stramann ao tratar de tais preceitos, teóricos e práticos, durante suas lições demonstrava, indiretamente, que se tornava necessária uma mudança metodológica no que se referia ao ensino da Educação Física escolar brasileira. De outra forma, também indicava que a formação superior ocorrida nas Escolas de Educação Física precisava ser repensada, buscando reformular, especialmente, as ações didático pedagógicas. Em seu depoimento, o Prof. Hildebrandt-Stramann menciona uma boa receptividade de suas concepções por parte dos(as) alunos(as) do CEFD, tanto da graduação, como da pósgraduação. Contudo, o mesmo parece não ter ocorrido com os(as) colegas professores(as), no contexto mais geral da UFSM, conforme é possível notar a partir de sua narrativa:

Professor Reiner Hildebrandt-Stramann: Bem, fica claro, agora, após dez anos, que esse paradigma mais cientifico que eu levei para lá foi um paradigma científico que nós podemos chamar das Ciências Sociais e Humanas, da Fenomenologia e, também, com métodos científicos diferentes dos métodos científicos que são usados em um paradigma científico da Ciência Natural ou nas Ciências Naturais. Em Santa Maria, talvez dominasse, ou ainda domine e dominou, uma compreensão da Ciência da Educação Física que foi orientada nas Ciências Naturais. Então, junto com essa dominação acontece também uma determinada compreensão da nossa área. Uma determinada compreensão do homem dentro dessa área. Uma compreensão do movimentar-se e uma determinante compreensão da imagem sobre os homens movimentando-se. Então, aqui, começa, como posso dizer, as discussões. Primeiro, e infelizmente, começa aqui, também, problemas na cooperação com alguns colegas que não, isso é minha visão, que não queriam entrar num discurso científico comigo sobre exatamente esses assuntos. Eu encontrei, no corpo docente, vários colegas que cooperaram comigo, que me apoiaram muito, mas, também 
encontrei colegas que não queriam aceitar uma outra visão dentro dessa ciência e, mais problemático, não só não aceitaram, mas, também, trabalharam contra um colega estrangeiro. Então, isso me deixou muito triste e decepcionado com relação a esses colegas. Eu tentei abrir, desde o início, uma discussão científica sobre paradigmas diferentes dentro da nossa ciência. Eu posso dizer que, infelizmente, eu não consegui abrir essa discussão, especialmente para os colegas que trabalharam no mestrado.

No trecho da narrativa destacado, o Prof. Reiner recorda-se, após dez anos de sua passagem pela UFSM, do convívio e das resistências percebidas, relacionadas às suas concepções sobre o campo pedagógico que perpassava o ensino da Educação Física no período. Se por um lado, Hildebrandt-Stramann conseguia desenvolver debates e ações em sala de aula, juntos dos(as) alunos(as) da graduação, especialização e pós-graduação, o mesmo parece não ter ocorrido em ambientes onde alguns professores(as) frequentavam. Provavelmente, tais resistências alocavam-se, especialmente, no entendimento distinto que o Prof. Reiner possuía sobre o modo como se deveria conduzir uma aula de Educação Física na escola.

Hildebrandt-Stramann defendia que os(as) alunos(as) buscassem, a todo momento, autonomia e independência, e as ações didáticas, por sua vez, deveriam ser conduzidas no sentido de atuarem em condições de corresponsabilidade entre alunos(as) e professores(as). Deste modo, esta atuação interligada pretendia, por um lado, instrumentalizar os sujeitos no sentido de buscarem soluções em conjunto para situações-problema geradas e, de outra forma, ampliar, sempre que possível, a complexidade das propostas de ensino, para que ocorresse a expansão do aprendizado em todos sentidos. Possibilitava-se, portanto, um processo de ensino-aprendizagem continuado através do desenvolvimento da capacidade de ação dos(as) alunos(as), tornando-os autônomos frente aos conhecimentos.

Embora o Prof. tenha mencionado a percepção de certa resistência, por parte de professores(as) do CEFD/UFSM, ao paradigma científico no qual suas investigações relacionavam-se, recordou-se de aspectos que, de outro modo, deram um sentido positivo ao trabalho desenvolvido na instituição. Durante o período em que permaneceu no Brasil, Hildebrandt-Stramann orientou trabalhos de professores(as) que, após terem obtido suas formações no CEFD/UFSM, inseriram-se em distintas instituições brasileiras. Acerca desse ponto o Prof. menciona:

Professor Reiner Hildebrandt-Stramann: Bom, como eu expliquei, eu trabalhei em três núcleos. Em cada núcleo eu tentei implantar, também, um trabalho de mestrado. Um trabalho analisou o ensino na formação dos estudantes, especialmente, o ensino nas disciplinas práticas da formação dos estudantes. Foi desenvolvido pelo Amauri [Amauri Aparecido Bássoli de Oliveira]. Um outro trabalho foi desenvolvido pelo Cardoso, professor Cardoso [Carlos Luiz Cardoso], 
agora, em Florianópolis. Este trabalho foi desenvolvido sobre a pergunta: como a gente pode desenvolver uma concepção na prática de ensino? Também foi um resultado do nosso curso de mestrado. E o terceiro trabalho que eu orientei foi o trabalho do professor Wenceslau [Wenceslau Virgílio Cardoso Leães Filho, que tentei desenvolver alguns estudos ecológicos sobre o movimentar, sobre a questão do movimentar-se fora da escola, no mundo vivido das crianças, mas, não só das crianças. Ele usou uma estrutura das zonas ecológicas que eu expliquei para ele, orientado no Bronfenbrenner. Bem, além disso, eu acho, eu desenvolvi muitos contatos e amizades com outros colegas que foram a Santa Maria, especialmente, colegas do nordeste, da Universidade de Pernambuco, do Recife e com os colegas de mestrado.

Ao encaminhar-se para a conclusão de sua narrativa, o Prof. Reiner menciona que, parece, ter estreitado o contato com professores(as) brasileiros, após ter deixado o país. Destaca, por exemplo, que no momento em que narrava sua experiência na presente entrevista, também estava concluindo a orientação da tese de doutoramento da professora Ingrid Mariane Becker. Assim, por mais que durante sua estada no país e, de modo específico, no CEFD/UFSM tenha enfrentado algumas resistências relacionadas às concepções de ensino que defendia, o que permaneceu daquele tempo e que traz satisfação ao recordar é o contato com professores(as) e o estabelecimento de novas parcerias, que possibilitaram a troca de ideias e construção de novas pesquisas.

Esses vínculos colaborativos podem ter contribuído para que a obra de Hildebrandt-Stramann se tornasse referência para o campo da Educação Física brasileira. Torna-se imperativo reiterarmos ainda, a significativa importância que suas concepções alcançaram, especialmente por focalizarem a relação estabelecida entre o sujeito e a sociedade, e como estas dimensões possuem contatos estreitos com o que está posto para o campo da Educação Física e do Esporte. Assim, conforme menciona Castro (2018), a mudança de paradigma em relação ao movimento humano, a cultura de movimento e o ensino do movimento apregoados pelo Prof. Reiner, contribuíram para a legitimação da Educação Física no contexto escolar e colaboraram para que sua concepção adentrasse também os muros da formação universitária.

Cabe mencionar também que o Prof. Reiner é autor de cerca de 200 artigos científicos e mais de 15 livros, sendo 10 publicados na Alemanha e seis no Brasil. Alguns de seus livros publicados, por meio de resenhas e textos elaborados por autores brasileiros como, por exemplo, Oliveira (2005), Batalha-Lemke (2008), Hatje \& Leães Filho (2018), prosseguem sendo disseminados no século XXI. E, neste novo século, em setembro de 2011, o próprio Prof. retornou ao Brasil para fazer uma "visita científica", na Universidade Federal do Recôncavo da Bahia (UFRB). Na ocasião participou de evento promovido pelo Grupo de Estudos e Pesquisas em Educação, Formação de Professores e Educação Física (GEPEFE), e prestou “Assessoria Internacional sobre Formação de Professores e Referências Curriculares Básicas para a Educação Física Escolar”, no Centro de Formação de Professores, localizado no campus de Amargosa da 
UFRB. No ano seguinte, em 2012, foi prestigiado com o título de Professor Honorífico da UFBA e, de 2012 até 2014, atuou como professor visitante desta instituição (CURRICULUM VITAE, 2014).

Por fim, o retorno mais recente do Prof. Reiner à UFSM ocorreu no ano de 2019, por ocasião da realização do Simpósio Internacional de Educação Física: currículo e didática (CEFD REALIZA..., 2019). O referido evento integrou um conjunto de ações, as quais compõem um projeto mais amplo, desenvolvido por intermédio de uma cooperação acadêmica internacional entre Alemanha e Brasil, que busca a construção de um novo currículo na área da Educação Física (SIMPÓSIO INTERNACIONAL..., 2019). Deste modo, no Simpósio, a colaboração do Prof. Reiner, especialista em didática, sinalizou possíveis caminhos a serem seguidos para efetivação deste anseio. Outrossim, tal circunstância nos permite refletir que, mesmo passadas mais de três décadas desde a primeira vez em que estivera na UFSM, parece que o legado deixado pelo Prof. Reiner permanecera significativo no transcurso do tempo. A partilha do presente parece, também, presentificar o passado, reconhecendo, (re)escrevendo e representando um elo que se conservou apesar dos conflitos vivenciados outrora.

\section{Referências}

BATALHA-LEMKE, J. Educação Física aberta à experiência - uma concepção didática em discussão. Reiner Hildebrandt-Stramann. Motrivivência, Florianópolis, ano XX, n. 31, p. 256-273, dez. 2008.

CASTRO, F. B. de. Educação Física aberta à experiência: um diálogo com as cinco teses de HildebrandtStramann (2009). Revista Kinesis, Santa Maria, v. 36, n. 3, p. 115-127, set./dez. 2018.

CEFD REALIZA... CEFD realiza primeiro Simpósio Internacional na área da Educação Física. Disponível em: https://www.ufsm.br/2019/09/03/simposio-internacional-de-educacao-fisica/ Acesso em: 24/07/2020.

GADDIS, John Lewis. Paisagens da história: como os historiadores mapeiam o passado. Tradução: Marisa Rocha Motta. Rio de Janeiro: Campus, 2003.

HATJE, M.; LEÃES FILHO, W. A modularização curricular para uma transformação didática ao ensino da educação física. Resenha. Revista Kinesis, Santa Maria v.36, n.2, p. 122-126, mai./ago. 2018.

HILDEBRANDT-STRAMANN. Reiner. Curriculum vitae. Programa de Pós-Graduação em Educação Física. UFSC, 2014.

MAZO, Janice Zarpellon. A história do Centro de Educação Física e Desportos da Universidade Federal de Santa Maria/UFSM: 25 anos. Santa Maria: UFSM, CEFD, 1997.

MAZO, J. Z. A história do Centro de Educação Física e Desportos da Universidade Federal de Santa Maria: um relato cronológico. Kinesis, Santa Maria, n. 10, p. 19-47, jul./dez. 1992. 
MAZO, Janice Zarpellon. O Centro de Educação Física da Universidade Federal de Santa Maria: percorrendo os caminhos de sua criação. 1993. 152 f. Dissertação (Mestrado em Ciência do Movimento Humano), Universidade Federal de Santa Maria, Santa Maria, 1993.

OLIVEIRA, A. A. B. de. Textos pedagógicos sobre o ensino da Educação Física. Revista Movimento, Porto Alegre, v. 11, n. 1, p. 171-182, jan./abr. 2005.

PESAVENTO, Sandra Jatahy. Fronteiras da história: uma leitura sensível do tempo. In: SCHÜLER, Fernando; AXT, Gunter; SILVA, Juremir Machado da. Fronteiras do pensamento: retratos de um mundo complexo. São Leopoldo: Editora UNISINOS, 2008. p. 179-190.

SIMPÓSIO INTERNACIONAL... Simpósio internacional de Educação Física: currículo e didática. Disponível em: https://www.ufsm.br/unidades-universitarias/cefd/simposio-internacional-de-educacaofisica-curriculo-e-didatica/ Acesso em: 27/07/2020.

UFRB RECEBE VISITA... UFRB recebe visita de professor da Universität Braunschweig. Disponível em: https://www.ufrb.edu.br/portal/ensino/2534-ufrb-recebe-visita-de-professor-dauniversitaet-braunschweig .Acesso em: 24/07/2020

\section{Como citar este artigo}

MAZO, J. Z.; BEGOSSI, T. D. Narrativa, memória e saberes: entrevista com o professor Reiner Hildebrandt-Stramann. Revista Kinesis, Santa Maria, Dossiê CEFD 50 anos, p.01-12, 2020.

* O presente trabalho foi realizado com apoio da Coordenação de Aperfeiçoamento de Pessoal de Nível Superior - Brasil (CAPES) - Código de Financiamento 001. 